\title{
Promoting psychology to students: embracing the multiplicity of research foci and method
}

\author{
Clare S. Rees* \\ School of Psychology and Speech Pathology, Curtin University, Perth, WA, Australia
}

\section{Edited by:}

Ying Guo, University of Cincinnati, USA

\section{Reviewed by:}

Ying Guo, University of Cincinnati, USA

Norzarina Mohd-Zaharim, Universiti Sains Malaysia, Malaysia

*Correspondence:

Clare S. Rees, School of Psychology and Speech Pathology, Curtin University, Perth, WA, Australia e-mail: c.rees@curtin.edu.au
In order for the discipline of psychology to continue to thrive it is imperative that future students are effectively recruited into the field. Research is an important part of the discipline and it is argued that the nature of psychological research is naturally one of multiplicity in topic and methodology and that promoting and highlighting this should be considered as a potentially effective recruitment strategy. In this study, a snap-shot of current research topics and methodologies was collected based on published papers from one typical academic psychology department in Australia. Fifty articles published in the period 2010-2013 were randomly selected and then grouped using content analysis to form topic clusters. Five main clusters were identified and included: Grief and Loss; Psychopathology; Sociocultural Studies; Attachment and Parenting; and Developmental Disorders. The studies spanned the full spectrum of research methodologies from quantitative to qualitative and had implications for assessment practices, diagnosis, prevention and treatment, education, and policy. The findings are discussed in terms of the unique characteristics of psychology as a discipline and how this diversity ought to be utilized as the main selling point of the discipline to future students.

Keywords: psychology, education, research methods

\section{INTRODUCTION}

The discipline of Psychology has been described as a "human science" because it intercepts both the field of humanities as well as the traditional sciences. However, despite this overlap, Psychology is a unique and separate discipline. It seeks to address questions about human nature by utilizing many of the empirical methods of the physical sciences yet at the same time the complexity of studying human nature makes psychological research inherently subjective and selective. Research methods within psychology cover a broad spectrum such as basic laboratory-based research, case studies, correlational studies and mixed methodologies. In the late 1970s a philosopher of science, Wilhelm Dilthey referred to the multiplicity of research methods employed in psychology as a necessary aspect of the discipline:

Psychology depends on different approaches compensating for each other's defects .... It seeks entry into mental life through many gates (Dilthey, 1976, p. 93).

In many ways the research that underpins the study of psychology is both linear and circular and the tension that exists between acknowledging the importance of the scientific method but at the same time acknowledging the notion that much of the field is concerned with phenomena that is largely outside of the realm of measurement creates a dialectic. This can make the study of psychology both unsettling/off-putting and attractive at the same time. In terms of attracting potential students to the discipline it may be important to use this dialectic as a selling point as opposed to attempting to falsely and artificially force psychology into one category or another, e.g., science or humanities.

Students new to the field of psychology tend to have false ideas as to what the general subject matter involves. For example,
Rowley et al. (2008) surveyed 169 honors students from a research active university in the United Kingdom. They found that in their first year of studying psychology, students believed that the subject was primarily concerned with uncovering underlying truths about human nature. It wasn't until the students reached second or third year that they were more likely to understand and appreciate the diversity of focus and perspectives in the discipline.

Interestingly, most of the published literature relating to research in psychology is concerned primarily with debating approaches to research methodology. For example, Breen and Darlaston-Jones (2010) argued that psychological research is dominated by positivism and a narrow preference for quantitative research at the expense of other equally rigorous forms of enquiry. They go on to propose that increasing the diversity within psychology "would enhance the applicability and relevance of the profession to addressing social issues that would lead to meaningful social change, which would certainly increase the 'real-world' impact of the research" (p.71). Some authors have argued that the focus on research methodologies in psychology has been an attempt to unify an otherwise fragmented discipline by searching for a unified research method. Henriques (2013) has suggested that this is a flawed endeavor and has instead proposed a "Unified Theory" which focuses on providing a conceptual map of the full breadth of psychological enquiry.

However, in order to accurately construct such a "map" it is first necessary to obtain a clear picture of the type of research currently being conducted within the discipline. A recent exploration of published studies from 2007-2013 using one of the leading psychology search engines, Psych Info, did not uncover one article providing an overview of representative research topics 
in psychology. For academic departments to remain financially viable it is vital that students are effectively recruited. For psychology this involves the use of effective marketing strategies that will generate interest in the topic but at the same time provide accurate information as to the nature of the course to be studied. With this in mind the purpose of the current paper was to investigate the current status of research in psychology in a typical academic psychology department. Focusing on one department was seen as a starting point for a subsequent larger study encompassing several Australian universities. However, as an initial step in the research process and because no other comparable studies could be identified, a purposive sample was selected. Information as to the topics and research methodologies currently being undertaken will help provide an accurate profile of the scope of psychology needed to assist in the effective recruitment of future students to the field.

\section{MATERIALS AND METHODS}

As the purpose of the research was to create a representative snapshot of published research in the field, inductive content analysis was the method employed. All published, peer-reviewed articles produced from the School of Psychology, Curtin University, Australia in a three year period (2010-2013) were collected. Next, 50 articles were randomly selected from the total list of published articles. These articles were then examined and grouped into clusters based on the topic of the research. Articles that did not fall into a major cluster were assigned minor clusters. Each article was also labeed as either quantitative, qualitative, mixed-method or review. Clusters groups were determined by the author who is an experienced research active academic. In order to ensure the trustworthiness of the data, member checks of the resultant cluster groups were conducted with the authors of the papers.

\section{RESULTS}

Five dominant clusters emerged. Each is described in detail below. Table 1 outlines the articles and indicates the associated research methodology used.

\section{GRIEF AND LOSS}

The studies in this cluster covered the full breadth of research from preliminary qualitative studies (Breen and O'Connor, 2010), intervention studies (Bentley et al., 2012) through to those concerned with policy and practice (Aoun et al., 2012, 2013; Breen, 2012). For example, the study by Breen and O'Connor (2010) explored the experience of grief amongst 21 adults whose family member had been killed in a traffic crash. Participants were drawn from 16 families and were aged between 24 and 71 years. Semi-structured interviews were conducted and analyzed from a grounded theory perspective. Participants described their grief as being "silenced" on a number of levels. Overall, the authors concluded that participants were communicating a "resistance to the dominant grief discourse" as their experiences did not align with the predominant view of grief as being a linear, staged-based process. Participants indicated a preference for a more holistic rather than symptom-focused model of care.

Aoun et al. (2012) conducted a review of bereavement services in palliative care and argued for a public health approach to the
Table 1 | Research Methodologies and Samples of the included studies by theme.

\begin{tabular}{|c|c|}
\hline Research theme & Research method \\
\hline Grief and loss & $\begin{array}{l}\text { Aoun et al. (2012): Review } \\
\text { Aoun et al. (2013): Quantitative } \\
\text { Breen and O'Connor (2010): Qualitative } \\
\text { Bentley et al. (2012): Quantitative } \\
\text { Breen (2012): Review }\end{array}$ \\
\hline Psychopathology & $\begin{array}{l}\text { Egan et al. (2011): Quantitative } \\
\text { Egan et al. (2012b): Review } \\
\text { Egan et al. (2012a): Quantitative } \\
\text { Fitt and Rees (2012): Quantitative } \\
\text { Kingdon et al. (2012): Quantitative } \\
\text { Lee and Rees (2011): Qualitative } \\
\text { Mazzucchelli (2010): Review } \\
\text { Priddis and Wallace (2011): Qualitative } \\
\text { Rees and Anderson (2013): Review } \\
\text { Steele et al. (2013): Quantitative }\end{array}$ \\
\hline Social cultural & $\begin{array}{l}\text { Bennett et al. (2012): Qualitative } \\
\text { Di Ciano et al. (2010): Qualitative } \\
\text { Dzidic and Green (2012): Mixed Method } \\
\text { Garvey (2011): Review } \\
\text { Hofmeester et al. (2012): Qualitative } \\
\text { Prandl et al. (2012): Review } \\
\text { Rooney et al. (2012): Quantitative } \\
\text { Syme et al. (2012): Mixed Method }\end{array}$ \\
\hline Parenting and attachment & $\begin{array}{l}\text { Howieson and Priddis (2011): Qualitative } \\
\text { Priddis and Wells (2010): Qualitative } \\
\text { Priddis and Wallace (2011): Qualitative } \\
\text { Priddis and Howieson (2012): Quantitative } \\
\text { Sanders and Mazzucchelli (2013): Review }\end{array}$ \\
\hline Developmental disorders & $\begin{array}{l}\text { Haynes et al. (2013): Quantitative } \\
\text { Kidd and Kaczmarek (2010): Qualitative } \\
\text { Pannekoek et al. (2012): Quantitative } \\
\text { Pearsall-Jones et al. (2010): Review } \\
\text { Pearsall-Jones et al. (2011): Mixed Method } \\
\text { Povee et al. (2012): Mixed Method } \\
\text { Sheikhi et al. (2013): Quantitative } \\
\text { Wilson et al. (2013): Quantitative }\end{array}$ \\
\hline
\end{tabular}

provision of such services. A public health approach would tailor provision of services according to a three-tiered model. In this model, interventions are either universal, selective or indicated and thus differ in intensity. At the universal level all bereaved are provided with information about bereavement, at the selective level those assessed as at-risk of developing complex needs are provided with non-professional support such as community support groups and at the indicated level those with complex needs are provided with specialist bereavement supports. The review strongly links recommendations to empirical studies showing that many people manage their grief effectively without the need for invasive interventions. As these studies in grief and loss reveal, a number of different research methodologies are employed form basic research through to translational research. 


\section{PSYCHOPATHOLOGY}

The studies included in this cluster ranged from those looking at particular psychological disorders such as depression (Mazzucchelli, 2010), eating disorders (Joyce et al., 2012; Egan et al., 2013), obsessive-compulsive disorder (OCD) (Lee and Rees, 2011; Fitt and Rees, 2012; Kingdon et al., 2012; Rees and Anderson, 2013), and substance abuse (Priddis and Wallace, 2011; Bright et al., 2013) through to those studying transdiagnostic factors considered to be pivotal in the development and maintenance of psychological disorders, such as perfectionism (Egan et al., 2011, 2012a,b; Steele et al., 2013). The studies included in this group had a diverse range of methodologies. The study by Joyce et al. (2012) studied the relationship between perfectionism and eating disorder pathology using structural equation modeling. A community sample of 202 women completed a number of questionnaires assessing conditional goal setting, self-oriented perfectionism and eating pathology. The resulting model indicated that shape and weight overvaluation and conditional goal-setting mediated the relationship between self-oriented perfectionism and eating pathology.

The study by Lee and Rees (2011) was a qualitative investigation of the treatment experiences and preferences of patients diagnosed with OCD. In particular, this study sought to determine if the experience of exposure therapy (the gold-standard psychological treatment for OCD) was as aversive as had been reported anecdotally. Thematic analysis of individual responses to semi-structured interviews indicated that participants found the treatment to be "challenging and stressful" but that the level of distress was moderated by the level of therapist support and explanation provided. Overwhelmingly, the participants were in support of the therapy acknowledging that it had been the necessary ingredient to their symptom improvement.

\section{SOCIAL CULTURAL STUDIES}

This research cluster included studies of indigenous Australians and mental health (Garvey, 2011; Bennett et al., 2012; Prandl et al., 2012), the mental health needs of immigrants (Di Ciano et al., 2010; Rooney et al., 2012) and social cultural influences on the environment (Dzidic and Green, 2012; Hofmeester et al., 2012; Syme et al., 2012). Rooney et al. (2012) constructed a measure to assess the level of ethnic identification of adults from diverse ethnic backgrounds. A second aim of developing the measure was to assess the level of ethnic identification with the host culture. They included 275 adults from ethnically diverse backgrounds who responded to 50 initial statements. Factor analysis of responses produced three factors: (1) Pride in ethnic background and language, (2) Liking for traditional and social activities of my ethnic group, and (3) Sense of belonging to this (host) country. The authors then tested the model on a further sample of 1007 adults. A final two-factor model was derived; (1) Ethnic Identity and (2) Sense of Belonging to host country.

Dzidic and Green (2012) utilized a mixed-method approach to studying community acceptance of non-potable groundwater use and sustainable urban design in Perth, Australia. The authors utilized a computer-based photo-elicitation survey to ascertain respondents acceptance of various degrees of aesthetic degradation, for example, discoloration of toilets due to use of groundwater. Eleven in-depth interviews were also conducted and the overall finding was that participants were accepting of some level of aesthetic degradation however social norms and pressures to "keep up appearances" is an obstacle to uptake of sustainable urban design.

\section{PARENTING AND ATTACHMENT}

This cluster included intervention studies for improving parentinfant relationships and general parenting skills (Priddis and Wells, 2010; Sanders and Mazzucchelli, 2013), studies specifically investigating affect regulation amongst parents (Howieson and Priddis, 2011; Priddis and Wallace, 2011) and studies of attachment patterns (Priddis and Howieson, 2012). The study by Priddis and Howieson (2012) compared attachment patterns with concurrent behavioral ratings in a sample of preschool children. The sample included 136 mother-infant dyads from diverse socio-economic backgrounds. No association between attachment patterns and behavioral ratings was found at preschool age, however follow-up of the same sample 7 years later revealed an association between compulsively insecure attachment patterns and levels of depression.

Sanders and Mazzucchelli (2013) published a review article that focused on the importance of integrating a self-regulation component to parent training programs as a way of improving parenting practices. They argued that parents with a strong self-regulatory capacity would be in a better position to promote self-regulation skills in their children.

\section{DEVELOPMENTAL DISORDERS}

Studies in this category covered developmental coordination disorder (DCD) (Pearsall-Jones et al., 2010, 2011; Pannekoek et al., 2012; Wilson et al., 2013), autism (Kidd and Kaczmarek, 2010), intellectual disability (Povee et al., 2012; Haynes et al., 2013), and attention deficit hyperactivity disorder (ADHD) (Sheikhi et al., 2013). Pearsall-Jones et al. (2010) reviewed the etiological pathways of DCD and ADHD and argued that although these developmental disorders tend to overlap and have some shared features such as prevalence and ratio of males to females with the disorders, they have different developmental pathways. They suggest that the causal pathways of developmental disorders are best considered a combination of genetic, epigenetic and environmental factors and that these factors evolve over time.

The study by Povee et al. (2012) utilized a mixed-method approach to study the impact on families of raising a child with Down's Syndrome. The study included 224 caregivers of children aged 4-25 years. The quantitative aspect of the study investigated the relationship between amount of maladaptive and autism-spectrum behaviors on family functioning. Although greater levels of these behaviors was associated with poorer family functioning, on the whole family functioning and marital adjustment did not differ from levels found in families with typically developing children.

\section{OTHER MINOR THEMES}

Several other minor research themes were observed and further illustrate the diversity in topic range within the discipline. These themes include; Computers and Online Environments 
(Burns and Roberts, 2013; Jerejian et al., 2013); music preferences (Yeoh and North, 2012); teaching and supervision (Grant et al., 2012; Schneider and Rees, 2012; Schofield and Grant, 2013) maternal stress and pregnancy issues (Doyle et al., 2013; Li et al., 2013) and forensic psychology (Halse et al., 2012; Mackenzie et al., 2012; Spiranovic et al., 2012).

\section{DISCUSSION}

The analysis of collected published articles for the period 2010-2013 revealed a wide range of topic and an even spread of research methodologies. The collection of studies illustrates the diversity of research foci in the discipline of psychology. The widely held notion that psychological research is restricted to studies of psychological disorder at the individual level is directly refuted by the results of this review. A further important observation is that research methodologies were very evenly spread with approximately half of the studies being quantitative and half qualitative or mixed methodology. Qualitative methodologies have gained increasing favor and the results of this study support the popularity of this approach. The results of this study suggest that the discipline is beginning to utilize a more even blend of research methodologies which is in line with the suggestions made by Breen and Darlaston-Jones (2010).

It should be acknowledged that the present investigation is limited to the study of one psychology department in Australia.

\section{REFERENCES}

Aoun, S. M., Breen, L. J., O'Connor, M., Rumbold, B., and Nordstrom, C. (2012). A public health approach to bereavement support services in palliative care. Aust. N.Z. J. Public Health 36, 14-16. doi: 10.1111/j.1753-6405.2012.00825.x

Aoun, S. M., O’Connor, M., Breen, L. J., Deas, K., and Skett, K. (2013). Testing models of care for terminally ill people who live alone at home: is a randomised controlled trial the best approach? Health Soc. Care Community 21, 181-190. doi: 10.1111/hsc.12002

Bennett, E., Hauck, Y. L., Bindahneem, S., Banham, V., Owens, M., Priddis, L. E., et al. (2012). The development of an interdisciplinary research agenda at ngala: an innovative case study. Neonatal Paediatr. Child Health Nurs. 15, 20-25.

Bentley, B., Aoun, S. M., O'Connor, M., Breen, L. J., and Chochinov, H. M. (2012). Is dignity therapy feasible to enhance the end of life experience for people with motor neurone disease and their family carers? BMC Palliat. Care 11:18. doi: 10.1186/1472-684X-11-18

Breen, L. J. (2012). The effect of caring on post-bereavement outcome: research gaps and practice priorities. Prog.
Palliat. Care 20, 27-30. doi: 10.1179/1743291X12Y.0000000003

Breen, L. J., and Darlaston-Jones, D. (2010). Moving beyond the enduring dominance of positivism in psychological research: implications for psychology in Australia. Aust. Psychol.45, 67-76. doi: 10.1080/00050060903127481

Breen, L. J., and O'Connor, M. (2010). Acts of resistance: breaking the silence of grief following traffic crash fatalities. Death Stud.34, 30-53. doi: 10.1080/07481180903372384

Bright, S. J., Bishop, B., Kane, R., Marsh, A., and Barratt, M. J. (2013). Kronic hysteria: exploring the intersection between Australian synthetic cannabis legislation, the media, and drug-related harm. Int. J. Drug Poloicy 24, 231-237. doi: 10.1016/j.drugpo.2012.12.002

Burns, S., and Roberts, L. (2013). Applying the theory of planned behaviour to predicting online safety behaviour. Crime Prev. Community Saf. 15, 48-64. doi: 10.1057/cpcs.2012.13

Di Ciano, T., Rooney, R., Wright, B., Hay, D., and Robinson, L. (2010). Postnatal social support group needs and explanatory models of Iraqi Arabic speaking women in the year following the birth

In order to capture a more comprehensive picture of the state of research in psychology this study requires replication and extension with a broader representation of the field. However, it offers an important first step in assessing the state of play in the discipline.

Psychology as a research field is thriving internationally but in order for it to continue to grow it is imperative to attract enthusiastic and capable researchers to the field. The current findings indicate that marketing initiatives in universities should consider showcasing examples of published research in order to clearly communicate the diversity that is possible when electing to study this field. As highlighted in this review, research in psychology crosses the full spectrum of human functioning and behavior. The impacts of psychological research can be seen in policy and practice developments, in community education, and in prevention and treatment. Rather than struggle to fit a round peg in a square hole, it may be more fruitful for efforts to focus on describing the discipline in terms of its rich topic diversity and methodological range.

Over the years psychology could be described as having an "identity crisis"; not fitting comfortably into either the pure sciences or the humanities but falling somewhere in-between. Interestingly, pioneers in the field of psychology such as Windt, James, Binet, and Freud, all used multiple methods, both quantitative and qualitative. It seems that contemporary psychology continues in this tradition.

of their baby in Perth, Western Australia. Adv. Ment. Health 9, 162-176. doi: 10.5172/jamh.9.2.162

Dilthey, W. (1976). Wilhelm Dilthey: Selected Writings. Cambridge: Cambridge University Press.

Doyle, J., Pooley, J. A., and Breen, L. (2013). A phenomenological exploration of the childfree choice in a sample of Australian women. J. Health Psychol.18, 397-407. doi: 10.1177/1359105312444647

Dzidic, P., and Green, M. (2012) Outdoing the Joneses: understanding community acceptance of an alternative water supply scheme and sustainable urban design. Landsc. Urban Plan.105, 266-273. doi: 10.1016/j.landurbplan.2011.12.023

Egan, S. J., Dick, M., and Allen, P. J. (2012a). An experimental investigation of standard setting in clinical perfectionism. Behav. Change 29, 183-195. doi: 10.1017/bec.2012.16

Egan, S. J., Wade, T. D., and Shafran, R. (2012b). The transdiagnostic process of perfectionism. Rev. Psicopatol. Psicol. Clin. 17, 279-294.

Egan, S. J., Watson, H. J., Kane, R. T., Nathan, P. R., McEvoy, P., and Fursland, A. (2013). Anxiety as a mediator between perfectionism and eating disorders. Cogn. Ther. Res. 37, 1-9. doi: 10.1007/s10608012-9516-x
Egan, S., Piek, J., Dyck, M., and Kane, R. (2011). The reliability and validity of the positive and negative perfectionism scale. Clin. Psychol. 15, 121-132. doi: 10.1111/j.17429552.2011.00029.x

Fitt, S., and Rees, C. (2012). Metacognitive therapy for obsessive compulsive disorder by videoconference: a preliminary study. Behav. Change 29, 213-229. doi: 10.1017/bec.2012.21

Garvey, D. C. (2011). Closing gaps, maintaining cadence and removing trampolines: a personal reflection on 20 years in health. Med. J. Aust. 194, 543-545.

Grant, J., Schofield, M. J., and Crawford, S. (2012). Managing difficulties in supervision: supervisors perspectives. J. Couns. Psychol.59, 528-541. doi: 10.1037/a0030000

Halse, A., Grant, J., Thornton, J., Indermaur, D., Stevens, G., and Chamarette, C. (2012). Intrafamilial adolescent sex offenders' response to psychological treatment. Psychiatry Psychol. Law 19, 221-235. doi: 10.1080/13218719.2011.561763

Haynes, A., Gilmore, L., Shochet, I., Campbell, M., and Roberts, C. (2013). Factor analysis of the self-report version of the strengths and difficulties questionnaire in a sample of children 
with intellectual disability. Res. Dev. Disabil.34, 847-854. doi: 10.1016/j.ridd.2012.11.008

Henriques, G. (2013). Evolving from methodological to conceptual unification. Rev. Gen. Psychol. 17, 168-173. doi: 10.1037/a0032929

Hofmeester, C., Bishop, B., Stocker, L., and Syme, G. (2012). Social cultural influences on current and future coastal governance. Futures 44, 719-729. doi: 10.1016/j.futures.2012.04.002

Howieson, J., and Priddis, L. (2011). Building resilience for separating parents through mentalizing and constructive lawyering techniques. Psychiatry Psychol. Law 18, 202-211. doi: 10.1080/13218711003739532

Jerejian, A. C. M., Reid, C., and Rees, C. S. (2013). The contribution of email volume, email management strategies and propensity to worry in predicting email stress among academics. Comput. Human Behav. 29, 991-996. doi: 10.1016/j.chb.2012.12.037

Joyce, F., Watson, H. J., Egan, S. J., and Kane, R. T. (2012). Mediators between perfectionism and eating disorder psychopathology in a community sample. Eat. Behav. 13, 361-365. doi: 10.1016/j.eatbeh.2012.07.002

Kidd, T., and Kaczmarek, E. (2010). The experiences of mothers home educating their children with autism spectrum disorder. Issues Educ. Res. 20, 257-275.

Kingdon, B. L., Egan, S. J., and Rees, C. S. (2012). The illusory beliefs inventory: a new measure of magical thinking and its relationship with obsessive compulsive disorder. Behav. Cogn. Psychother. 40, 39-53. doi: $10.1017 / S 1352465811000245$

Lee, Y. H., and Rees, C. S. (2011). Is exposure and response prevention treatment for obsessive-compulsive disorder as aversive as we think? Clin. Psychol. 15, 17-21. doi: 10.1111/j.1742-9552.2011.00001.x

Li, J., Robinson, M., Malacova, E., Jacoby, P., Foster, J., and van Eekelen, A. (2013). Maternal life stress events in pregnancy link to children's school achievement at age 10 years. J. Pediatr. 162, 483-489. doi: 10.1016/j.jpeds.2012.09.007

Mackenzie, G., Spiranovic, C., Warner, K., Stobbs, N., Indermaur, D., Roberts, L. D., et al. (2012).
Sentencing and public confidence: results from a national Australian survey on public opinions towards sentencing. Aust. N.Z. J. Criminol. 45, 45-65. doi: $10.1177 / 0004865811431328$

Mazzucchelli, T. G. (2010). Behavioral activation for depression: a clinician's guide. Behav. Change 27, 266-268. Available online at: http://search.informit.com.au/ documentSummary; $\mathrm{dn}=762387633$ 148870;res=IELHEA

Pannekoek, L., Rigoli, D., Piek, J. P., Barrett, N. C., and Schoemaker, M. (2012). The revised Dcdq: is it a suitable screening measure for motor difficulties in adolescents? Adapt. Phys. Activ. Q. 29, 81-97.

Pearsall-Jones, J. G., Piek, J. P., and Levy, F. (2010). Etiological pathways for developmental coordination disorder and attention-deficit/hyperactivity disorder: shared or discrete? Expert Rev. Neurother. 10, 491-494. doi: 10.1586/ern.10.20

Pearsall-Jones, J. G., Piek, J. P., Steed, L., McDougall, M. R., and Levy, F. (2011). Monozygotic twins concordant and discordant for DCD: two sides to the story. Twin Res. Hum. Genetics 14, 79-87. doi: 10.1375/twin.14.1.79

Povee, K., Roberts, L., Bourke, J., and Leonard, H. (2012). Family functioning in families with a child with down syndrome: a mixed methods approach. J. Intellect. Disabil. Res. 56, 961-973. doi: 10.1111/j.13652788.2012.01561.x

Prandl, K. J., Rooney, R., and Bishop, B. J. (2012). Mental health of Australian aboriginal women during pregnancy: identifying the gaps. Arch. Womens Ment. Health 15, 149-154. doi: 10.1007/s00737-0120276-0

Priddis, L., and Howieson, N. D. (2012). Insecure attachment patterns at five years. what do they tell us? Early Child Dev. Care 182, 45-58. doi: 10.1080/03004430.2010. 537334

Priddis, L. E., and Wallace, M. A. (2011). Exploration of intergenerational aspects of affect regulation in the context of substance abuse. Fam. J. 19, 147-153. doi: 10.1177/ 1066480710397121

Priddis, L. E., and Wells, G. (2010). Improving parent-infant relationships: an innovative group approach to working with families to improve parent-infant relationships within a community setting. Neonatal Paediatr. Child Health Nurs. 13, 20-24. Available online at: http://search.informit.com.au/ documentSummary;dn $=543133460$ 819292;res=IELHEA

Rees, C. S., and Anderson, R. A. (2013). A review of metacognition in psychological models of obsessivecompulsive disorder. Clin. Psychol. 17, 1-8. doi: 10.1111/cp.12001

Rooney, R., Nesdale, D., Kane, R. Hattie, J., and Goonewardene, R (2012). The development of the universal ethnic identity scale (ueis) for use in an Australian context. Aust. Psychol. 47, 238-248. doi 10.1111/j.1742-9544.2011.00040.x

Rowley, M., Hartley, J., and Larkin, D. (2008). Learning from experience: the expectations and experiences of first year undergraduate psychology students. J. Further High. Educ. 32, 399-413. doi 10.1080/03098770802538129

Sanders, M. R., and Mazzucchelli, T. G.,(2013). The promotion of selfregulation through parenting interventions. Clin. Child Fam. Psychol. Rev. 16, 1-17. doi: 10.1007/s10567013-0129-z

Schneider, K., and Rees, C. (2012). Evaluation of a combined cognitive behavioural therapy and interpersonal process group in the psychotherapy training of clinical psychologists. Aust. Psychol. 47, 137-146. doi 10.1111/j.1742-9544.2012.00065.x

Schofield, M. J., and Grant, J. (2013) Developing psychotherapists' competence through clinical supervision: protocol for a qualitative study of supervisory dyads. BMC Psychiatry 13:12. doi: 10.1186/1471244X-13-12

Sheikhi, A. R., Martin, N., Hay, D. and Piek, J. P. (2013). Phenotype refinement for comorbid attention deficit hyperactivity disorder and reading disability. Am. J. Med. Genet. B Neuropsychiatr. Genet. 162B, 44-54. doi: 10.1002/ ajmg.b.32119

Syme, G. J., Dzidic, P., and Darnbacher, J. M. (2012). Enhancing science in coastal management through understanding its role in the decision making network. Ocean
Coast. Manage. 69, 92-101. doi 10.1016/j.ocecoaman.2012.08.012

Spiranovic, C. A., Roberts, L. D., and Indermaur, D. (2012). What predicts punitiveness? an examination of predictors of punitive attitudes towards offenders in Australia. Psychiatry Psychol. Law 19, 249-261. doi: 10.1080/13218719. 2011.561766

Steele, A. L., Waite, S., Egan, S. J., Finnigan, J., Handley, A., and Wade, T. (2013). Psycho-education and group cognitive-behavioural therapy for clinical perfectionism: a case-series evaluation. Behav. Cogn. Psychother. 41, 129-143. doi: 10.1017/S1352465812000628

Wilson, A., Piek, J. P., and Kane, R. (2013). The mediating role of social skills in the relationship between motor ability and internalizing symptoms in pre-primary children. Infant Child Dev. 22, 151-164. doi: 10.1002/icd.1773

Yeoh, J. P. S., and North, A. C. (2012). The effect of musical fit on consumers' preferences between competing alternate petrols. Psychol. Music 40, 709-719. doi: $10.1177 / 0305735611408994$

Conflict of Interest Statement: The author declares that the research was conducted in the absence of any commercial or financial relationships that could be construed as a potential conflict of interest.

Received: 18 June 2013; accepted: 02 October 2013; published online: 21 October 2013.

Citation: Rees CS (2013) Promoting psychology to students: embracing the multiplicity of research foci and method. Front. Psychol. 4:774. doi: 10.3389/fpsyg. 2013.00774

This article was submitted to Educational Psychology, a section of the journal Frontiers in Psychology.

Copyright (ㄷ 2013 Rees. This is an openaccess article distributed under the terms of the Creative Commons Attribution License (CC BY). The use, distribution or reproduction in other forums is permitted, provided the original author(s) or licensor are credited and that the original publication in this journal is cited, in accordance with accepted academic practice. No use, distribution or reproduction is permitted which does not comply with these terms. 